\title{
Management of Chiari malformation in syndromic and nonsyndromic craniosynostosis
}

\author{
Ako Matsuhashi, MD, Kenichi Usami, MD, PhD, Eitaro Ishisaka, MD, and Hideki Ogiwara, MD, PhD \\ Division of Neurosurgery, National Center for Child Health and Development, Tokyo, Japan
}

OBJECTIVE Although the association between Chiari malformation (CM) and craniosynostosis is well recognized, management remains controversial. There are differences in the clinical course of CM in syndromic craniosynostosis (SC) patients and nonsyndromic craniosynostosis (NSC) patients. Still unclear is whether cranial expansion surgery, foramen magnum decompression (FMD), or both should be conducted and when the appropriate timing of surgery should be. Here, the authors retrospectively reviewed the clinical data at their institution to investigate the optimal management of $\mathrm{CM}$ associated with SC and NSC.

METHODS The authors retrospectively analyzed the clinical records of 163 children with craniosynostosis who underwent surgical treatment at the National Center for Child Health and Development between April 2002 and May 2018.

RESULTS Twelve (10\%) of 119 children with NSC and 14 (31.8\%) of 44 children with SC were radiologically diagnosed with $\mathrm{CM}$. The median age at which $\mathrm{CM}$ was radiologically diagnosed was 7 months. Of the 12 NSC patients with $\mathrm{CM}, 1(8 \%)$ was symptomatic with gait disturbance. This patient underwent FMD following expansion surgery. Of the 14 SC patients with CM, 8 (57.1\%) were symptomatic with central sleep apnea. For SC patients with symptomatic $\mathrm{CM}$, cranial expansion surgery alone was conducted in 2 cases, FMD was conducted after cranial expansion in 4 cases, and FMD was conducted first and additional expansion surgery was then conducted in 2 cases. In all cases, symptoms of CM improved after completing this series of surgeries. Regarding patients with asymptomatic $\mathrm{CM}$, cranial expansion surgery alone was performed, and none of the patients showed symptoms of CM thereafter in both $\mathrm{SC}$ and NSC cases.

CONCLUSIONS Multiple surgeries tend to be necessary for symptomatic CM in both SC and NSC, while no patient with asymptomatic $\mathrm{CM}$ became symptomatic after cranial expansion surgery.

https://thejns.org/doi/abs/10.3171/2019.9.PEDS19261

KEYWORDS syndromic craniosynostosis; Chiari malformation; cranial expansion; foramen magnum decompression

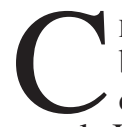

HIARI malformation (CM) type I is characterized by downward herniation of the caudal part of the It may develop progressively due to a disproportion between hindbrain growth and an abnormally small posterior fossa.$^{1,13,19}$ In children with craniosynostosis, CM occurs as a consequence of decreased volume of posterior cranial fossa due to premature fusion of cranial sutures. ${ }^{3,23,24}$ Surgical intervention for cranial expansion is often needed in children with craniosynostosis, not only for cosmetic reasons but also to prevent increased intra- cranial pressure (ICP) and its consequences, such as neurological and cognitive disorders. ${ }^{3,10}$ However, the optimal management of $\mathrm{CM}$ in the setting of craniosynostosis is not well established. Patients with syndromic craniosynostosis (SC), who are identified with several genetic disturbances, present with complex congenital anomalies, including multiple affected cranial sutures, hand and foot abnormalities, and varying degrees of midface hypoplasia. Therefore, the management of CM differs for patients with CM and SC than for those with $\mathrm{CM}$ and nonsyndromic craniosynostosis (NSC). ${ }^{3,7,12,16}$ Experiences gained

ABBREVIATIONS $\mathrm{CM}=$ Chiari malformation; $\mathrm{CSA}=$ central sleep apnea; $\mathrm{FMD}=$ foramen magnum decompression; $\mathrm{ICP}=$ intracranial pressure; NSC = nonsyndromic craniosynostosis; $\mathrm{SC}=$ syndromic craniosynostosis; VPS = ventriculoperitoneal shunt.

SUBMITTED May 3, 2019. ACCEPTED September 27, 2019.

INCLUDE WHEN CITING Published online December 20, 2019; DOI: 10.3171/2019.9.PEDS19261. 
from treating patients with $\mathrm{CM}$ without craniosynostosis may not be relevant due to the fact that patients with craniosynostosis have fundamental differences in skull growth. ${ }^{22}$

In this series, we present cases of CM associated with SC and NSC treated at our institution to investigate the optimal surgical management.

\section{Methods \\ Study Design}

A retrospective chart review was performed at our institution, the National Center for Child Health and Development. The patients were children who underwent surgical treatment for craniosynostosis between April 2002 and May 2018. This study was approved by the ethics committee of our institution. Demographic data, diagnoses, imaging studies, operative interventions, and clinical follow-up were evaluated.

\section{Diagnostic Evaluation}

Inspection of craniofacial formation, palpation of a child's head, and abnormal head circumference suggested craniosynostosis. The diagnosis of craniosynostosis was confirmed with 3D CT scans by assessing premature suture fusions. A beaten-copper appearance of the skull suggested elevated ICP. ${ }^{4} \mathrm{~A}$ beaten-copper appearance is seen significantly more commonly in patients with craniosynostosis. The incidence of beaten-copper appearance increases as the child grows, suggesting that it is age dependent and evidence of long-term increased ICP. ${ }^{23,25}$ Though ICP was not monitored directly by means of lumbar puncture or ICP monitoring, ophthalmological examinations were routinely performed for papilledema. Elevated ICP was identified comprehensively by radiological examinations and physical examinations, including fundoscopic examinations and overall development. CM type I was identified on MRI as cerebellar tonsillar herniation of more than 5 $\mathrm{mm}$ below the foramen magnum without the presence of meningomyocele. ${ }^{6}$ The presence of hydrocephalus was also assessed radiologically and presented as abnormally enlarged cerebral ventricles. SC is suggested in children with multiple-suture synostosis and distinctive malformations in their extremities and craniofacial region, and genomic examinations were conducted in those patients whose parents agreed to the test.

\section{Surgical Procedures \\ Endoscope-Assisted Suturectomy}

This procedure was conducted in patients younger than 6 months of age. A strip craniectomy was performed on the fused sutures (the widths of which were $2 \mathrm{~cm}$ ), and the fused bone was removed. ${ }^{5,14,15}$

\section{Cranial Vault Distraction}

Generally, we performed posterior cranial vault distraction for expansion. A parietooccipital craniotomy was conducted, and an occipital craniectomy was added to the upper edge of the transverse sinus. Typically, 4 distractors were placed at the parietal bone. The distractors were
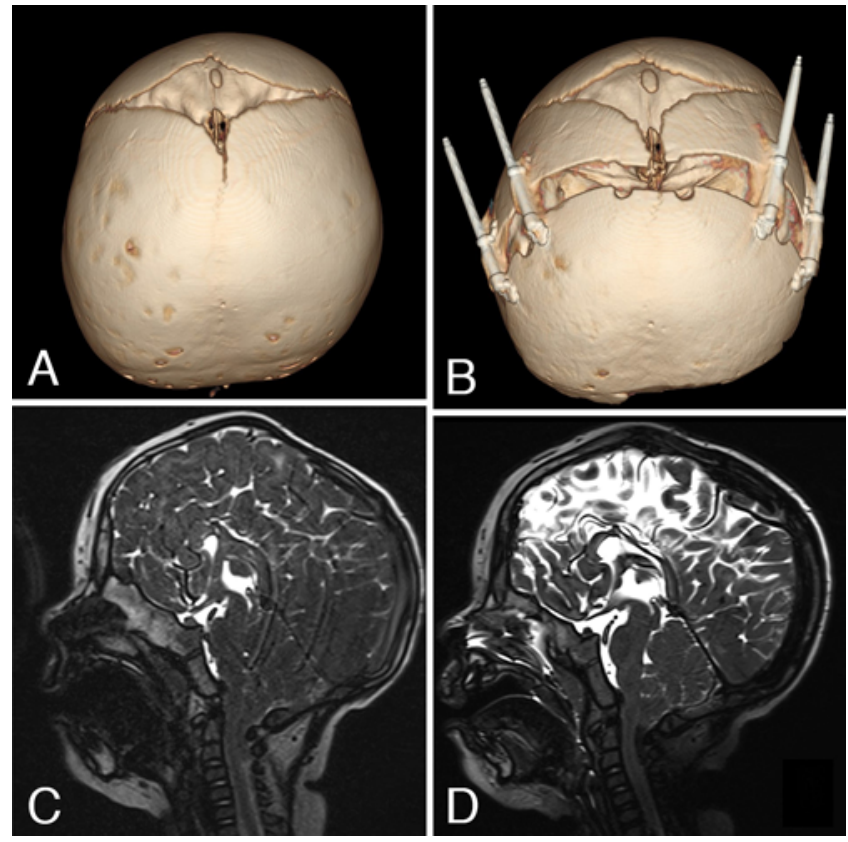

FIG. 1. Cranial vault distraction. 3D CT scans showing the skull of a patient with craniosynostosis before treatment $(\mathrm{A})$ and after the placement of distractors and expansion (B). Sagittal T2-weighted MR images obtained in a patient with $\mathrm{CM}$ associated with SC before treatment (C) and after cranial vault expansion surgery (D). Figure is available in color online only.

activated $0.5-1.0 \mathrm{~mm} /$ day until they reached $20-25 \mathrm{~mm}$. 3D CT was conducted after the distraction to confirm adequate advancement of the skull and brain expansion. After the activation was stopped, a consolidation period of approximately 4-6 months followed, and when adequate osteogenesis was achieved, all distractors were removed (Fig. 1). ${ }^{20}$

\section{Foramen Magnum Decompression}

Suboccipital craniectomy and removal of the $\mathrm{C} 1$ posterior arch were performed (Fig. 2). The outer layer of the dura mater was excised. A duraplasty was usually conducted when a syrinx was present. However, when there was a prominent marginal sinus or occipital sinus, we only performed bony decompression.

\section{Follow-Up and Outcome Measurement}

We followed patients with annual CT, MRI, sleep studies, ophthalmological examinations, and neurodevelopmental evaluations until the age of 5 years, and then a follow-up examination was performed once every 2-3 years until adolescence. We reduced ionizing radiation to half of its usual dose when we acquired CT scans in patients with craniosynostosis. Considering there were patients who were recently referred, the mean follow-up period was 7.1 years. Symptoms of CM were identified with central sleep apnea (CSA) detected in the sleep study or in an abnormal neurological examination. We typically used a score of greater than 10 on the apnea/hypopnea index as indication for foramen magnum decompression (FMD) to 


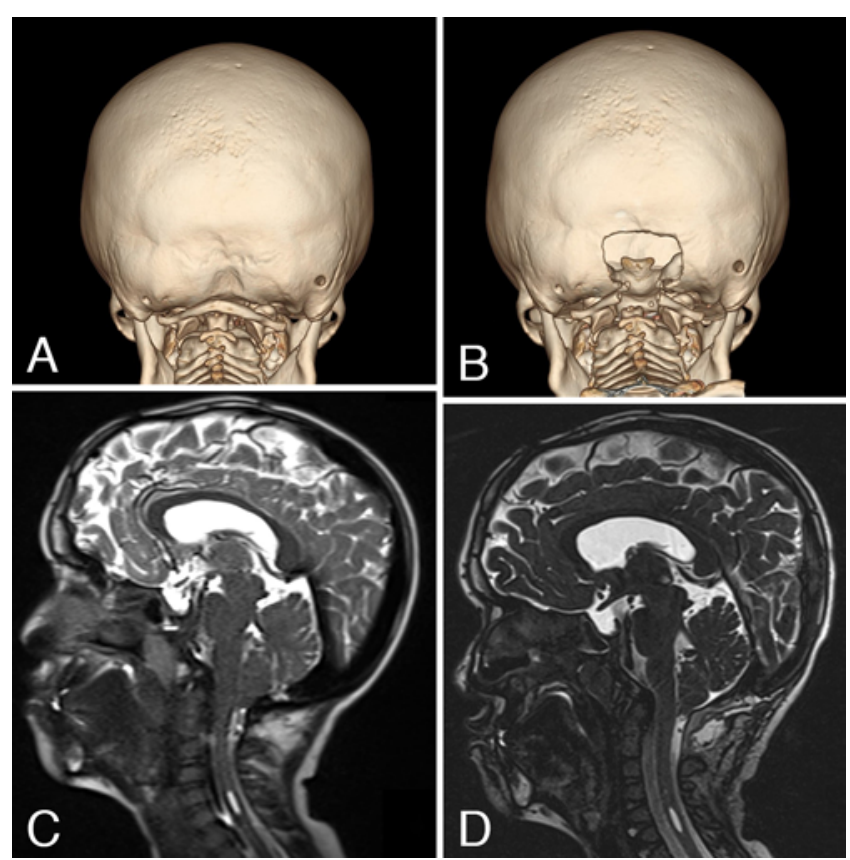

FIG. 2. FMD. 3D CT scans demonstrating the skull of a patient before (A) and after (B) FMD. Sagittal T2-weighted MR images showing a patient with CM associated with SC before (C) and after (D) FMD. The postoperative MR image (D) demonstrates a less crowded posterior fossa and slightly smaller syrinx. Figure is available in color online only.

treat the CSA. The presence of a syrinx was also assessed using MRI. We considered a patient to be symptomatic when he/she had neurological symptoms, including CSA or a syrinx.

\section{Statistical Analysis}

This study included comparisons of the incidence of $\mathrm{CM}$ in patients with NSC versus SC and the incidence of CM in patients with multisuture closure versus singlesuture closure. All statistical analyses were performed with JMP Pro 13.0 software (SAS Institute). A standard chi-square test was used to compare the frequencies of categorical data in each group. Any $\mathrm{p}$ value $<0.05$ was considered statistically significant.

\section{Results}

\section{Patient Characteristics}

We identified 163 children with craniosynostosis who underwent a surgical procedure during the designated period (Table 1). Of the 163 children, 44 had SC and 119 had NSC. Genomic examinations had been performed in $75 \%$ of the children. The group with SC included 9 patients with Apert syndrome, 9 with Crouzon syndrome, 8 with Pfeiffer syndrome, and 3 with Saethre-Chotzen syndrome. Others had Muenke syndrome, Beare-Stevenson cutis gyrata syndrome, Treacher Collins syndrome, or were unidentified.

Taking both SC and NSC patients into consideration, 87 patients had multisuture closure, and 76 patients had single-suture closure. The rates of CM among these two
TABLE 1. Patient characteristics

\begin{tabular}{lccc}
\hline \multicolumn{1}{c}{ Characteristic } & NSC & SC & p Value \\
\hline No. of patients & 119 & 44 & \\
\hline Sex & & & \\
\hline Female & $38(31.9)$ & $21(47.7)$ & \\
\hline$\quad$ Male & $81(68.1)$ & $23(52.3)$ & \\
\hline Age at presentation (range), mos & $12.1(0-74)$ & $12.0(0-87)$ & \\
\hline No. of patients w/ CM & $12(10.0)$ & $14(31.8)$ & 0.001 \\
\hline
\end{tabular}

Values are presented as the number (\%) of patients or as the mean age (range) in months.

groups were $28.7 \%(25 / 87)$ and $1.3 \%(1 / 76)$, respectively $(\mathrm{p}<0.001)$. Moreover, $\mathrm{CM}$ was diagnosed in $25(43.1 \%)$ of 58 patients with lambdoid suture closure. Twelve (10.0\%) of 119 children with NSC and $14(31.8 \%)$ of 44 children with SC were radiologically diagnosed with $\mathrm{CM}$. The rate of CM was significantly higher in SC according to univariate analysis $(\mathrm{p}=0.001)$. However, multivariate analysis of multisuture closure, lambdoid suture closure, and SC showed that lambdoid closure was a significant risk factor for $\mathrm{CM}$, but neither multisuture closure nor SC was an independent risk factor.

In our study population of SC patients, 5 patients (55.6\%) with Crouzon syndrome and 3 patients (37.5\%) with Pfeiffer syndrome were diagnosed with CM. No patients with Apert or Saethre-Chotzen syndrome had CM. Univariate analysis showed that, compared to other syndromes, Crouzon syndrome had a significantly higher rate of CM ( $\mathrm{p}=0.008$; Table 2).

\section{Diagnosis and Treatment of CM in NSC}

The clinical presentations of the 12 patients with $\mathrm{CM}$ associated with NSC are summarized in Table 3. Among the 12 NSC patients with CM, 11 had multiple sutures involved; the sagittal suture was involved in 11 patients, the coronal suture was involved in 4, and the lambdoid suture was involved in 11. Expansion surgery was performed in all patients. Of the 12 NSC patients with CM, $1(8 \%)$ had symptomatic gait disturbance. This patient underwent FMD after expansion surgery, and the gait disturbance

TABLE 2. Incidence of CM

\begin{tabular}{|c|c|c|c|c|}
\hline \multirow[b]{2}{*}{ Variable } & \multirow[b]{2}{*}{$\begin{array}{l}\text { No. of } \\
\text { Cases }\end{array}$} & \multirow[b]{2}{*}{$\begin{array}{l}\text { No. w/ } \\
\text { CM (\%) }\end{array}$} & \multicolumn{2}{|c|}{$p$ Value } \\
\hline & & & $\begin{array}{c}\text { Univariate } \\
\text { Analysis }\end{array}$ & $\begin{array}{c}\text { Multivariate } \\
\text { Analysis }\end{array}$ \\
\hline Multisuture closure & 87 & $25(28.7)$ & $<0.0001$ & 0.3369 \\
\hline Lambdoid suture closure & 58 & $25(43.1)$ & $<0.0001$ & $<0.0001$ \\
\hline SC & 44 & $14(31.8)$ & 0.0014 & 0.4178 \\
\hline Apert & 9 & $0(0)$ & 0.1788 & \\
\hline Crouzon & 9 & $5(55.6)$ & 0.0008 & \\
\hline Pfeiffer & 8 & $3(37.5)$ & 0.0878 & \\
\hline Saethre-Chotzen & 3 & $0(0)$ & 0.4463 & \\
\hline Other & 15 & $6(40.0)$ & 0.0076 & \\
\hline
\end{tabular}


TABLE 3. Demographic and clinical presentation of NSC patients with CM

\begin{tabular}{|c|c|c|c|c|c|}
\hline Patient No. & Age (mos), ${ }^{*}$ Sex & Suture Involved & Symptom & Procedure & Outcome \\
\hline 1 & $15, M$ & Sagittal, coronal (U), lambdoid & Gait disturbance, syrinx & Expansion, FMD & Syrinx improved \\
\hline 2 & $24, \mathrm{~F}$ & Sagittal, lambdoid & NS & Expansion & Stable \\
\hline 3 & $13, \mathrm{M}$ & Sagittal, lambdoid & NS & Expansion, ETV, FMD & Stable \\
\hline 4 & $2, M$ & Sagittal, lambdoid (U) & NS & Expansion & Stable \\
\hline 5 & $6, M$ & Lambdoid & NS & Expansion & Stable \\
\hline 6 & $4, F$ & Sagittal, lambdoid & NS & Expansion & Stable \\
\hline 7 & $4, \mathrm{~F}$ & Sagittal, coronal (U), lambdoid & NS & Expansion & Stable \\
\hline 8 & $24, \mathrm{M}$ & Sagittal, coronal (U), lambdoid & NS & Expansion & Stable \\
\hline 9 & $46, M$ & Sagittal, coronal, lambdoid & Syrinx & Expansion & Syrinx improved \\
\hline 10 & $7, \mathrm{M}$ & Sagittal, lambdoid & NS & Expansion, VPS & Stable \\
\hline 11 & $20, M$ & Sagittal, lambdoid & NS & Expansion & Stable \\
\hline 12 & $31, \mathrm{~F}$ & Sagittal & Syrinx & Expansion & Syrinx improved \\
\hline
\end{tabular}

ETV = endoscopic third ventriculostomy; NS = not specified; $U$ = unilateral.

${ }^{*}$ Age at diagnosis of $\mathrm{CM}$.

improved postoperatively. All asymptomatic patients with $\mathrm{CM}$ at presentation continued to not have symptoms of $\mathrm{CM}$ after cranial expansion surgery. CSF diversion was conducted in 2 patients. One patient underwent an endoscopic third ventriculostomy, and another patient underwent ventriculoperitoneal shunt (VPS) placement after expansion surgery to treat progressive hydrocephalus. One asymptomatic patient underwent preventive FMD because the parents strongly desired surgery.

\section{Diagnosis and Treatment of CM in SC}

The clinical presentations of the 14 patients with $\mathrm{CM}$ associated with SC are summarized in Table 4. The median patient age at which $\mathrm{CM}$ was radiologically diagnosed was 7 months. Eight patients (57.1\%) had CSA determined by a sleep study and 2 patients also had syringomyelia shown on MRI. The 8 symptomatic patients underwent an operative procedure for symptomatic CM. The firstline treatment for $\mathrm{CM}$ was cranial vault distraction. If symptoms associated with CM did not improve after this procedure, then FMD was performed. Whenever patients showed symptoms of increased ICP that required urgent treatment, such as papilledema and bradycardia, shunt surgery was performed to control the ICP. When the patients were too young for cranial vault distraction (typically younger than 6 months of age), FMD or suturectomy was performed as the first treatment. Our treatment algorithm is shown in Fig. 3.

Thus, cranial vault distraction alone was performed in 2 cases (patients 4 and 14), FMD was performed after cranial vault distraction in 4 cases (patients 5, 8, 9, and

TABLE 4. Demographic and clinical presentation of SC patients with CM

\begin{tabular}{|c|c|c|c|c|c|}
\hline Patient No. & Age (mos), ${ }^{*}$ Sex & Syndrome & Symptom & Procedure & Outcome \\
\hline 1 & $16, \mathrm{M}$ & Unidentified & NS & Expansion (includes suturectomy), VPS & Stable \\
\hline 2 & $1, F$ & Unidentified & CSA & Expansion, FMD, VPS & CSA improved \\
\hline 3 & $61, \mathrm{~F}$ & Crouzon & NS & Expansion & Stable \\
\hline 4 & $89, \mathrm{~F}$ & Crouzon & CSA, syrinx & Expansion & CSA \& syrinx improved \\
\hline 5 & $0, F$ & Pfeiffer II & CSA & Expansion, FMD & CSA improved \\
\hline 6 & $38, M$ & Unidentified & NS & Expansion & Stable \\
\hline 7 & $6, F$ & Pfeiffer II & CSA & Expansion (includes suturectomy), FMD, VPS & Stable \\
\hline 8 & $36, M$ & Crouzon & CSA, syrinx & Expansion, FMD & CSA \& syrinx improved \\
\hline 9 & $19, \mathrm{M}$ & Crouzon & CSA & Expansion, FMD & CSA improved \\
\hline 10 & $3, M$ & Pfeiffer I & CSA & Expansion (includes suturectomy), FMD, VPS & CSA improved \\
\hline 11 & $1, M$ & Beare-Stevenson & NS & Expansion, VPS & Stable \\
\hline 12 & $8, F$ & Crouzon & NS & Expansion & Stable \\
\hline 13 & $1, M$ & Unidentified & NS & Expansion & Stable \\
\hline 14 & $2, M$ & Unidentified & CSA & Expansion, ETV, VPS & CSA improved \\
\hline
\end{tabular}

\footnotetext{
${ }^{*}$ Age at diagnosis of $\mathrm{CM}$.
} 


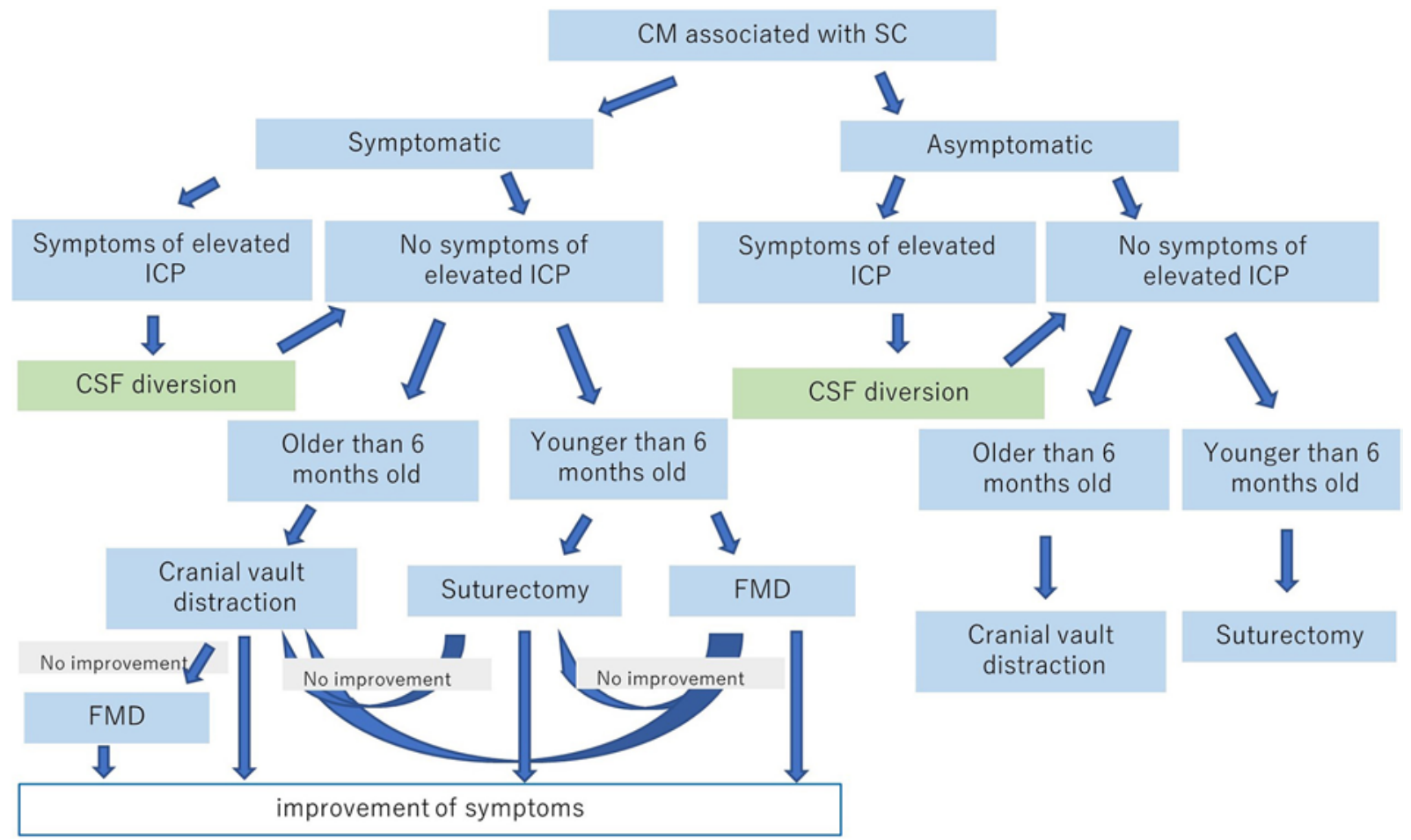

FIG. 3. Treatment algorithm for CM associated with SC. Figure is available in color online only.

10), and FMD was performed as the first procedure followed by cranial vault distraction in 2 cases (patients 2 and 7) (Fig. 4). As for the 4 patients who required FMD after cranial vault distraction, CSA and tonsillar descent demonstrated on imaging studies improved initially after the expansion surgery but gradually recurred. FMD was conducted promptly once CSA was detected. The median period between cranial vault distraction and FMD was 45 months (range 9-64 months). A VPS was placed prior to those surgeries in 4 patients and after expansion surgery in 1 patient due to symptoms of elevated ICP. During this series of surgeries, CSA had persisted until the completion of the final surgery. Postoperatively, CSA improved in all patients after the series of surgeries was completed.

As for the patients with asymptomatic CM associated with SC, cranial vault expansion was performed in all cases to prevent the CM from becoming symptomatic, as well as to treat the underlying cranial deformity. Two patients

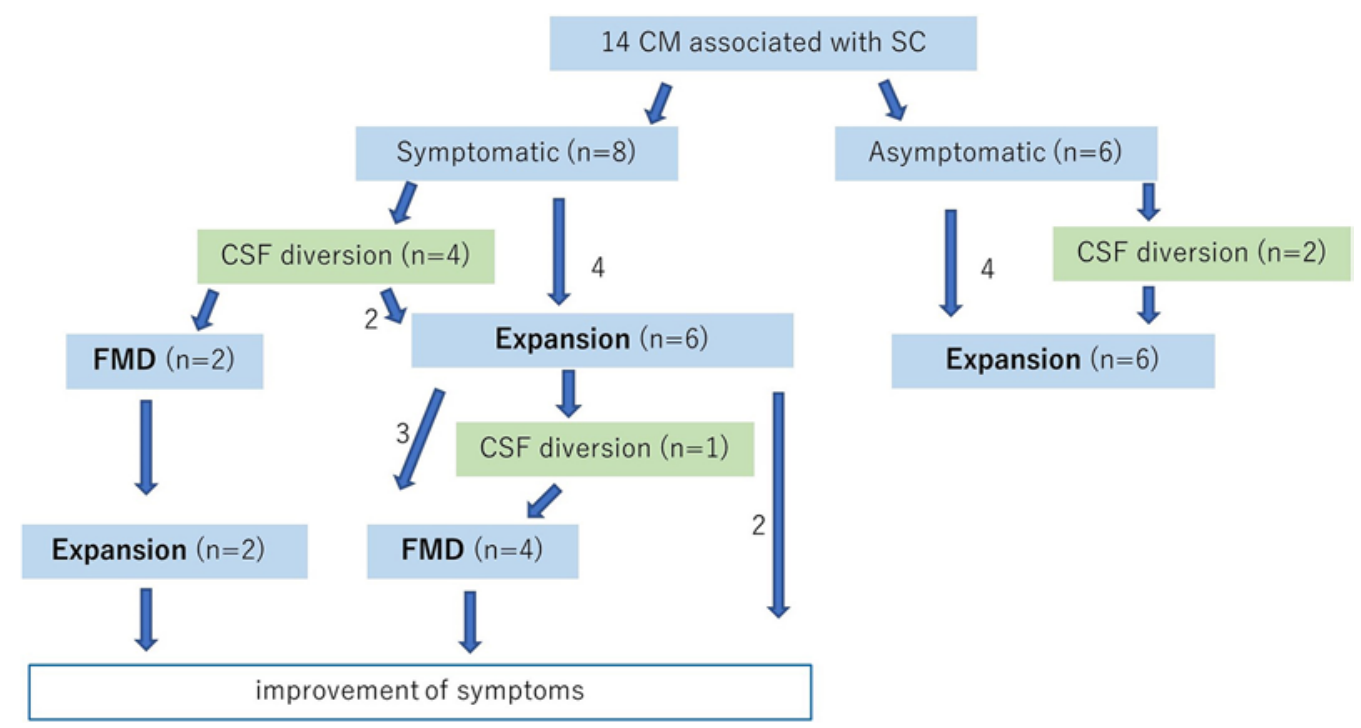

FIG. 4. The clinical course of patients with CM associated with SC. Figure is available in color online only. 
who had symptoms of elevated ICP underwent insertion of a VPS, and none of them showed symptoms of CM after the expansion surgery.

\section{Discussion}

We have presented a series of patients with symptomatic CM associated with SC and NSC, who underwent cranial vault distraction, FMD, or both and were routinely followed up with radiological examinations and sleep studies. Postoperatively, symptoms improved in all patients.

\section{Incidence of CM in Patients With Craniosynostosis}

In our study, $\mathrm{CM}$ was radiologically demonstrated by both SC and NSC. The univariate analysis showed that the incidence of $\mathrm{CM}$ was significantly higher in patients with SC (31.8\%) compared to those with NSC and in patients with multisuture craniosynostosis $(28.7 \%)$ compared to those with single-suture craniosynostosis. However, multivariate analysis showed that lambdoid suture closure was an independent risk factor for CM. Though there are several previous reports suggesting that children with lambdoid synostosis were more likely to have associated CM than other patients with craniosynostosis, there have been no prior studies that have statistically investigated whether lambdoid suture synostosis is an independent risk factor. ${ }^{8,22,23}$ Among patients with SC, previous studies have reported that the incidences of CM in Crouzon and Pfeiffer syndromes were estimated to be around $70 \%$ and $50 \%-80 \%$, respectively. ${ }^{1,9,11} \mathrm{CM}$ is reported to be common in cases of Crouzon syndrome due to the high incidence of early lambdoid suture closure. ${ }^{8}$ In our series, rates of $\mathrm{CM}$ in Apert, Crouzon, and Pfeiffer syndromes were $0 \%$, $55.6 \%$, and $37.5 \%$ respectively. According to the results of our univariate analysis, the incidence of $\mathrm{CM}$ was significantly higher in patients with Crouzon syndrome, which is consistent with the past reports.

\section{Management of CM in Craniosynostosis}

There have been previous reports in which cranial expansion surgery and/or FMD were conducted to treat CM associated with craniosynostosis; however, its optimal management has still remained a matter of debate. ${ }^{17,18,22,24}$

In our series, in patients with CM associated with NSC, cranial expansion surgery was conducted as the first-line treatment in all cases, regardless of the presence of symptoms. Eight of 12 patients had radiological improvement, such as the ascent of the cerebellar tonsils and reduction in crowding of the foramen magnum. All asymptomatic patients continued to be asymptomatic after the expansion surgery, although two of them underwent CSF diversion to treat progressive hydrocephalus. One patient with gait disturbance underwent both cranial expansion surgery and FMD.

Regarding asymptomatic patients with $\mathrm{CM}$ associated with SC, cranial expansion surgery was conducted as the first-line treatment. Although radiological improvement was not significant, none of these patients required FMD during the follow-up period. For patients with symptomatic CM, cranial expansion was conducted first in $75 \%$ (6/8). Among these 6 cases, 2 patients (33\%) improved by undergoing cranial expansion surgery alone, and 4 patients (67\%) later required FMD to treat symptoms of CM.

Among the 14 patients with CM in association with SC, a VPS was placed in 7. A VPS was placed in 5 patients with symptomatic CM. A VPS was placed in 5 of 8 patients with Pfeiffer syndrome. Three patients with Pfeiffer syndrome who underwent placement of a VPS also had symptomatic CM. This is compatible with the fact that Pfeiffer syndrome presents with a compilation of complex medical issues, including hydrocephalus and CM, compared to other syndromes. ${ }^{11}$ CSF diversion was conducted prior to expansion surgeries when there were acute symptoms of elevated ICP.

Leikola et al. investigated changes in cerebellar tonsillar herniation after cranial expansion and concluded that cranial expansion surgery had a positive impact on the resolution of cerebellar tonsillar herniation in cases of asymptomatic NSC by increasing the intracranial volume. ${ }^{17}$ They also suggested that posterior expansion surgery was especially effective. This is compatible with our study findings demonstrating that no patient with asymptomatic $\mathrm{CM}$ and NSC treated with expansion surgery developed symptoms after surgery. The Leikola et al. study was limited to NSC, but our study additionally investigated cases of CM in SC. Since we had no group of asymptomatic children with CM in SC who did not undergo any surgical treatment, it is impossible to conclude, but our data indicate that no child who underwent surgical interventions became symptomatic, which suggests that the concept indicated by Leikola et al. can be expanded to asymptomatic cases of SC.

Levitt et al. reported on a patient with Crouzon syndrome in whom the $\mathrm{CM}$ resolved after a cranial expansion procedure without performing suboccipital decompression. ${ }^{18}$ They demonstrated several theories of elevated ICP in SC, such as jugular venous stenosis in CS that leads to increased venous pressure and subsequent hydrocephalus, as well as a reduction in overall cranial volume that leads to hydrocephalus. They hypothesized that cranial expansion surgery reduced the craniocephalic disproportion that was responsible for elevated ICP, which mitigated the downward force of pressure on the cerebellar tonsils, causing CM. Our study showed that $67 \%$ (4/6) of patients with symptomatic CM were treated with FMD after expansion surgery, but 2 patients improved by undergoing cranial expansion surgery alone. Although there remains a possibility that additional FMD will be required, our study supports the practice of conducting cranial expansion surgery first followed by observing whether the symptoms of $\mathrm{CM}$ resolve without performing FMD.

In our study, patients with symptomatic $\mathrm{CM}$ and $\mathrm{SC}$ required a mean of 2.9 interventions (not including CSF diversion procedures) to treat symptoms of $\mathrm{CM}$, whereas 3 interventions were conducted to treat symptomatic CM and NSC. Thus, multiple surgeries, including multiple expansion surgeries and FMD, tend to be necessary when treating symptomatic $\mathrm{CM}$ associated with both SC and NSC.

Our study is retrospective, and therefore the timing and types of examinations and the follow-up lengths are not consistent among the patients. Some patients were diagnosed with CM or declared symptomatic at an older age 
because they were not referred to our institution at an early stage. This may have had effects on the treatment course because, had patients been referred to our institution earlier and expansion surgery been conducted at an early stage, the CM might have resolved without FMD. Reviewing the literature, there are 6 cases of CM in SC patients who underwent expansion surgeries and did not require FMD during the follow-up period. . $18,21,26$ Their ages at the time of expansion surgery ranged from 3 months to 11 years (mean 39.7 months, median 10.5 months). Other studies reporting on $\mathrm{CM}$ patients treated with expansion surgeries and/or FMD do not contain sufficient information regarding the age at diagnosis or treatment of craniosynostosis and CM to determine whether expansion surgery conducted at an early stage might result in fewer cases requiring FMD later on to treat symptoms of CM.1,11,22,23 Further studies are needed to investigate the optimal timing of treatment.

\section{Conclusions}

The incidence of CM is significantly higher in patients with lambdoid suture closure. No patients with asymptomatic CM went on to become symptomatic after cranial expansion surgery in those with both SC and NSC. Although $25 \%$ of the patients with symptomatic CM and SC improved by undergoing cranial expansion surgery alone, multiple surgeries tend to be necessary for symptomatic CM associated with craniosynostosis. However, all cases were successfully managed with sufficient surgical interventions.

\section{References}

1. Addo NK, Javadpour S, Kandasamy J, Sillifant P, May P, Sinha A: Central sleep apnea and associated Chiari malformation in children with syndromic craniosynostosis: treatment and outcome data from a supraregional national craniofacial center. J Neurosurg Pediatr 11:296-301, 2013

2. Ahmad F, Evans M, White N, Nishikawa H, Dover S, Solanki G, et al: Amelioration of Chiari type 1 malformation and syringomyelia following posterior calvarial distraction in Crouzon's syndrome - a case report. Childs Nerv Syst 30:177-179, 2014

3. Arts S, Delye H, van Lindert EJ: Intraoperative and postoperative complications in the surgical treatment of craniosynostosis: minimally invasive versus open surgical procedures. J Neurosurg Pediatr 21:112-118, 2018

4. Bogdanović M, Radnić B, Savić S, Popović V, Durmić T: Copper-beaten skull appearance as a response of chronically increased intracranial pressure. Am J Forensic Med Pathol 40:58-60, 2019

5. Chong S, Wang KC, Phi JH, Lee JY, Kim SK: Minimally invasive suturectomy and postoperative helmet therapy: advantages and limitations. J Korean Neurosurg Soc 59:227-232, 2016

6. Chotai S, Medhkour A: Surgical outcomes after posterior fossa decompression with and without duraplasty in Chiari malformation-I. Clin Neurol Neurosurg 125:182-188, 2014

7. Chumas PD, Cinalli G, Arnaud E, Marchac D, Renier D: Classification of previously unclassified cases of craniosynostosis. J Neurosurg 86:177-181, 1997

8. Cinalli G, Renier D, Sebag G, Sainte-Rose C, Arnaud E, Pierre-Kahn A: Chronic tonsillar herniation in Crouzon's and Apert's syndromes: the role of premature synostosis of the lambdoid suture. J Neurosurg 83:575-582, 1995
9. Cinalli G, Spennato P, Sainte-Rose C, Arnaud E, Aliberti F, Brunelle F, et al: Chiari malformation in craniosynostosis. Childs Nerv Syst 21:889-901, 2005

10. Di Rocco C, Velardi F: Acquired Chiari type I malformation managed by supratentorial cranial enlargement. Childs Nerv Syst 19:800-807, 2003

11. Fearon JA, Rhodes J: Pfeiffer syndrome: a treatment evaluation. Plast Reconstr Surg 123:1560-1569, 2009

12. Goldstein JA, Paliga JT, Wink JD, Bartlett SP, Nah HD, Taylor JA: Earlier evidence of spheno-occipital synchondrosis fusion correlates with severity of midface hypoplasia in patients with syndromic craniosynostosis. Plast Reconstr Surg 134:504-510, 2014

13. Gurbuz MS, Karaaslan N, Caliskan T, Unal E, Berkman MZ: Comparison of the surgical results for foramen magnum decompression with and without duraplasty in chiari malformation type 1. Turk Neurosurg 25:419-424, 2015

14. Jimenez DF, Barone CM: Early treatment of coronal synostosis with endoscopy-assisted craniectomy and postoperative cranial orthosis therapy: 16-year experience. J Neurosurg Pediatr 12:207-219, 2013

15. Jimenez DF, Barone CM, Cartwright CC, Baker L: Early management of craniosynostosis using endoscopic-assisted strip craniectomies and cranial orthotic molding therapy. Pediatrics 110:97-104, 2002

16. Judy BF, Swanson JW, Yang W, Storm PB, Bartlett SP, Taylor $\mathrm{JA}$, et al: Intraoperative intracranial pressure monitoring in the pediatric craniosynostosis population. J Neurosurg Pediatr 22:475-480, 2018

17. Leikola J, Hukki A, Karppinen A, Valanne L, Koljonen V: The evolution of cerebellar tonsillar herniation after cranial vault remodeling surgery. Childs Nerv Syst 28:1767-1771, 2012

18. Levitt MR, Niazi TN, Hopper RA, Ellenbogen RG, Ojemann JG: Resolution of syndromic craniosynostosis-associated Chiari malformation Type I without suboccipital decompression after posterior cranial vault release. J Neurosurg Pediatr 9:111-115, 2012

19. Nishikawa M, Sakamoto H, Hakuba A, Nakanishi N, Inoue Y: Pathogenesis of Chiari malformation: a morphometric study of the posterior cranial fossa. J Neurosurg 86:40-47, 1997

20. Park DH, Yoon SH: Transsutural distraction osteogenesis for 285 children with craniosynostosis: a single-institution experience. J Neurosurg Pediatr 17:230-239, 2016

21. Sandberg DI, Navarro R, Blanch J, Ragheb J: Anomalous venous drainage preventing safe posterior fossa decompression in patients with chiari malformation type I and multisutural craniosynostosis. Report of two cases and review of the literature. J Neurosurg 106 (6 Suppl):490-494, 2007

22. Scott WW, Fearon JA, Swift DM, Sacco DJ: Suboccipital decompression during posterior cranial vault remodeling for selected cases of Chiari malformations associated with craniosynostosis. J Neurosurg Pediatr 12:166-170, 2013

23. Strahle J, Muraszko KM, Buchman SR, Kapurch J, Garton HJL, Maher CO: Chiari malformation associated with craniosynostosis. Neurosurg Focus 31(3):E2, 2011

24. Tahiri Y, Bartlett SP, Gilardino MS: Evidence-based medicine: nonsyndromic craniosynostosis. Plast Reconstr Surg 140:177e-191e, 2017

25. Tuite GF, Evanson J, Chong WK, Thompson DN, Harkness WF, Jones BM, et al: The beaten copper cranium: a correlation between intracranial pressure, cranial radiographs, and computed tomographic scans in children with craniosynostosis. Neurosurgery 39:691-699, 1996

26. Winston KR, Stence NV, Boylan AJ, Beauchamp KM: Upward translation of cerebellar tonsils following surgical expansion of supratentorial cranial vault: a unified biome- 
chanical explanation of Chiari type I. Pediatr Neurosurg 50:243-249, 2015

\section{Disclosures}

The authors report no conflict of interest concerning the materials or methods used in this study or the findings specified in this paper.

\section{Author Contributions}

Conception and design: Ogiwara, Matsuhashi. Acquisition of data: Matsuhashi, Usami, Ishisaka. Analysis and interpretation of data: Ogiwara, Matsuhashi. Drafting the article: Matsuhashi. Critically revising the article: Ogiwara. Reviewed submitted version of manuscript: Usami, Ishisaka. Approved the final version of the manuscript on behalf of all authors: Ogiwara. Statistical analysis: Matsuhashi.

\section{Correspondence}

Hideki Ogiwara: National Center for Child Health and Development, Tokyo,Japan. hideki_o@d5.dion.ne.jp. 